\title{
Process Anatomy for High Aspect Ratio Micro-Hole Drilling with Short Micro-Second Pulses Using a CW Single-Mode Fiber
}

\author{
Jay Tu ${ }^{1}$, Ted Lehman ${ }^{1}$, Alexander G. Paleocrassas ${ }^{1}$, Wm. Ray Harp ${ }^{1}$, Satoru Noguchi ${ }^{2}$ \& Etsuji Ohmura ${ }^{2}$ \\ ${ }^{1}$ Department of Mechanical and Aerospace Engineering, North Carolina State University, EBIII, Raleigh, NC, \\ USA \\ ${ }^{2}$ Division of Materials and Manufacturing Science, Graduate School of Engineering, Osaka University, 2-1 \\ Yamada-oka, Suita, Osaka, Japan \\ Correspondence: Jay Tu, Department of Mechanical and Aerospace Engineering, North Carolina State University, \\ EBIII, Raleigh, NC 27695, USA. E-mail: jftu@ncsu.edu
}

Received: May 14, 2013 Accepted: June 13, 2013 Online Published: July 1, 2013

doi:10.5539/apr.v5n4p1 URL: http://dx.doi.org/10.5539/apr.v5n4p1

\begin{abstract}
The objective of this paper is to establish a detailed process anatomy of a micro-hole drilling process using a CW single-mode $300 \mathrm{~W}$ fiber laser with short micro-second pulses. For the drilling process with a one micro-second laser pulse, the process started with drastic evaporation and concluded with melt ejection approximately 150 micro-seconds later. It was concluded that two distinct hole drilling mechanisms occurred, one as adiabatic evaporation by the high power initial spike of the laser beam and one as melt ejection by the low power laser energy deposition. The drilling process time line was established based on the measurements by several in-process sensors, such as photodiodes, a high-speed camera, and a spectrometer. The theoretical modeling zoomed in the early stage of the process to investigate the hole formation which could not be observed experimentally. Both experimental and theoretical results were then compared to determine the laser-material interaction mechanisms among three media involved in the process: laser, material, and vapour/plasma. Finally, a series of temporal anatomy diagrams, denoted as process anatomy, were presented to describe the entire drilling process, including process temperature, laser energy deposition, hole formation, and material removal mechanisms.
\end{abstract}

Keywords: micro-hole drilling, laser ablation, microsecond pulse, fiber laser, melt ejection

\section{Introduction}

Laser drilling is an important industrial process to produce various sizes of holes for critical applications, such as cooling holes in turbine components. Typical laser pulse durations for laser drilling are in the nano-, pico- and femto-second ranges. Ultra-short-pulse lasers operate in the femto-second $\left(10^{-15} \mathrm{sec}\right)(\mathrm{fs})$ or pico-second $\left(10^{-12}\right.$ $\mathrm{sec}$ ) (ps) ranges to produce peak power density in the range of $10-1,000 \mathrm{GW} / \mathrm{cm}^{2}$. The holes produced with ultra-short pulses usually exhibit a clean finish because melting is not significant. However, the Material Removal Rate (MRR) is usually very low, for example, in the range of 10-200 nm/pulse for steels with a Ti: Sapphire femto-second laser (Bauerle, 2000). Breitling et al. (2004) presented fundamental aspects in machining of metals with short and ultra-short laser pulses. Mao et al. (2007) presented detailed high speed photography images of laser ablation mechanisms using short and ultra-short laser pulses. The micro-hole drilling process using nanosecond $\left(10^{-9} \mathrm{sec}\right)(\mathrm{ns})$ pulses usually produces holes in metal with acceptable quality, but, in general, worse than those by ultra-short lasers because melting is more significant. The material removal rate is usually in the order of $1-10 \mu \mathrm{m} / \mathrm{pulse}$. The power density of these lasers is in the range of $\mathrm{GW} / \mathrm{cm}^{2}$.

Laser drilling using long pulses in the range of several hundred microseconds $\left(10^{-6} \mathrm{sec}\right)$ to several milliseconds $\left(10^{-3} \mathrm{sec}\right)$ rely on mostly on melting to remove material because their power densities typically are below $10^{7}$ $\mathrm{W} / \mathrm{cm}^{2}$. The hole quality is usually low and the hole diameter is large due to significant melting. For example, in the experiments presented in Low and Li (2002) and Low et al. (2004), a Q-switiched 400W Nd:YAG laser was used to produce a pulse at $1.0 \mathrm{~ms}$, with pulse energy up to $7 \mathrm{~J}$ and peak power over $7 \mathrm{~kW}$. Using multiple pulses and with $\mathrm{O}_{2}$ as the assist gas, it could drill through a $2.5 \mathrm{~mm}$ stainless steel plate with a hole diameter approximately $600 \mu \mathrm{m}$. Similarly, Pandey et al. (2006), with a similar laser, conducted laser drilling with pulse durations ranging from 490 to $890 \mu \mathrm{s}$, pulse energy $0.5 \mathrm{~J}$, and argon gas as the assist gas. Kayukov et al. (1998) 
applied a single pulse from an Nd:YAG laser for up to $40 \mathrm{~J}$ in energy and $20 \mathrm{~ms}$ in pulse duration, with 3-5 kW peak power, to drill blind holes in different metals. For chromium steel, they achieved $6.5 \mathrm{~mm}$ deep blind hole with a single pulse at $17.5 \mathrm{~J}$ with a power density below $10^{6} \mathrm{~W} / \mathrm{cm}^{2}$. The blind hole demonstrated a large opening similar to a nail head shape over $1 \mathrm{~mm}$ in diameter and an average waist diameter about $300 \mu \mathrm{m}$.

In summary, the laser drilling process can be evaporation dominated or melting dominated depending on the pulse duration. In comparison, the body of work regarding short microsecond laser drilling/ablation is small. It is expected that the evaporation and melting both play an important role in the short microsecond drilling process. It is the objective of this paper to establish the drilling mechanisms and the temporal characteristics of the short microsecond drilling process, to be depicted in a series of diagrams, denoted as process anatomy.

This paper is organized as follows. First, the time line of the short microsecond drilling process is established based on the measurements of several in-process sensors, including photo-diodes, a high speed camera, and a spectrometer. Theoretical modeling is then used to zoom in the early hole formation stage which cannot be observed experimentally. Both experimental and theoretical results are then compared to determine the laser-material interaction mechanisms. Finally, a series of temporal anatomy diagrams, denoted as process anatomy, are presented to describe the entire drilling process by a one micro-second laser pulse. The body of a manuscript opens with an introduction that presents the specific problem under study and describes the research strategy.

\section{Review of Short Microsecond Pulse Drilling}

Garnov et al. (2004) performed laser ablation using pulse durations between $150 \mathrm{~ns}$ and $4.5 \mu \mathrm{s}$ on samples of stainless steel, aluminum, alumina ceramics, and graphite with a Q-switched Nd:YAG laser that used an optical fiber as part of the resonator to produce the desired pulse length. They reported an MRR at $11 \mu \mathrm{m} / \mathrm{pulse}$ with a power density of $20 \mathrm{MW} / \mathrm{cm}^{2}$ and pulse duration of $4.5 \mu$ s for stainless steel.

The advance of laser technology in the last decade has produced many high power lasers with very high beam quality. For example, Trippe et al. (2004) used a Q-switched Nd:YAG slab laser to produce pulses between $30 \mu$ s and $150 \mu$ s with power densities up to $220 \mathrm{MW} / \mathrm{cm}^{2}$. With a single pulse, they drilled holes in steel with diameters between $80 \mu \mathrm{m}$ and $120 \mu \mathrm{m}$ and depths from about $120 \mu \mathrm{m}$ to $700 \mu \mathrm{m}$ with argon gas. Their experimentally determined drilling speed was reported as $6 \mathrm{~m} / \mathrm{s}$. They also presented a dimensionless 2D model of free boundary problem and they computed the time for vaporization to be approximately 100 nanoseconds. Kreutz et al. (2007) applied this drilling technique to drill cooling holes in turbine components with multiple pulses (percussion drilling) combined with oxygen, helium, and argon assist gasses. Walther et al. (2008) combined the above Nd:YAG slab laser and the DPSS Nd:YAG laser to achieve very high aspect ratio percussion drilling (5 mm through holes with 170-180 $\mu \mathrm{m}$ waist diameter). Walther et al. (2008) utilized a flash lamp pumped Nd:YAG slab laser (FM015, LASAG) with a beam quality as $\mathrm{M}^{2}=2$ and it can produce pulses with durations from 100 to $500 \mu \mathrm{s}$ and a laser energy of $0.64 \mathrm{~J}$. This excellent beam quality allows a focus spot size 45 $\mu \mathrm{m}$ in diameter, producing a power density of $220 \mathrm{MW} / \mathrm{cm}^{2}$, as compared with $\mathrm{M}^{2}=22-38,600 \mu \mathrm{m}$ spot size, and approximately $3 \mathrm{MW} / \mathrm{cm}^{2}$ for the laser used in Low and Li (2002) and Voisey et al. (2002). Walther et al. (2008) also utilized a diode-pumped solid state (DPSS) Nd:YAG laser (Powergator 1064, Lambda Physik) which has a beam quality of $\mathrm{M}^{2}=1.7$, with a spot size of $42 \mu \mathrm{m}, 17 \mathrm{~ns}$ pulse, and $1.8 \mathrm{~mJ}$ pulse energy, producing a power density over $20 \mathrm{GW} / \mathrm{cm}^{2}$.

Most interestingly, the development of high power, single-mode fiber laser has established a new level of beam quality. For example, Harp et al. (2008) conducted micro-hole drilling with a $300 \mathrm{~W}, \mathrm{CW}, \mathrm{Yb}$-doped fiber laser (YLR-300, IPG), which has a near perfect beam quality $\mathrm{M}^{2}=1.04$ and the beam can be focused down to $10 \mu \mathrm{m}$ with a $100 \mathrm{~mm}$ lens. It can also be modulated to produce pulses from $1 \mu \mathrm{s}$ to any length of pulse duration. The modulated pulses all contain an initial spike at $1,500 \mathrm{~W}$, followed by a constant power at $300 \mathrm{~W}$, to reach a peak power density of $1.9 \mathrm{GW} / \mathrm{cm}^{2}$ and $380 \mathrm{MW} / \mathrm{cm}^{2}$ at the steady state. In comparison with ns-, ps-, and fs-lasers, the peak power of this modulated fiber laser pulse is low but its excellent beam quality allows for tight focusing to reach very high power density.

The feasibility of laser drilling with such a CW laser via modulation control was demonstrated by Harp et al. (2008), in which pulses from 15-40 $\mu$ s were used to produce holes with diameters from 40 to $100 \mu \mathrm{m}$ and depths from 25 to $50 \mu \mathrm{m}$. This work indicated that, by using high beam quality lasers, micro-hole drilling with pulse durations in the short microsecond range (1-10 $\mu \mathrm{s})$ has become feasible for applications which require moderate material removal depth per pulse, narrow opening (due to much smaller beam spot sizes), and moderate hole quality (due to moderate melt ejection).

In this paper, we focus on a single pulse drilling process of blind holes on a stainless steel substrate with pulse 
durations of 1-8 $\mu$ s using a $300 \mathrm{~W}, \mathrm{CW}$ single-mode fiber laser. In this study, the micro-hole drilling technique investigated in Harp et al. (2008) has been greatly extended and it is now possible, with a single $1 \mu$ s pulse, to produce a blind hole $167 \mu \mathrm{m}$ in depth and $19 \mu \mathrm{m}$ in the opening diameter on a $0.8 \mathrm{~mm}$ stainless steel plate.

\section{Summary of Experimental Results}

\subsection{Profiles of Modulated Fiber Laser Pulses}

A continuous-wave, single-mode, Yb-doped fiber laser (YLR-300, IPG) was used to drill blind holes on 316 stainless steel plates (SUS 316). This laser emitted a beam with a wavelength of $1,075 \mathrm{~nm}$ and a CW, steady-state power output of $300 \mathrm{~W}$. In this study, an external control circuit was developed with a capability of modulating laser pulses with durations from $1 \mu \mathrm{s}$ to $1 \mathrm{~s}$. This laser modulation control is different from Q-switching as the laser power remains constant while the deposited energy is determined by the pulse duration.

The modulated pulse of the laser was measured by an InGaAs photodiode (Thorlabs 410/M) through a $10 \mu \mathrm{m}$ pinhole to avoid saturating the photodiode. An oscilloscope (Tektronix $3012 \mathrm{~B}$ ) with a $100 \mathrm{MHz}$ sampling rate was used to measure the signal from the photodiode and to determine the actual laser pulse duration.

Figure 1 illustrates the measured profiles of the $1-\mu$ s and $15-\mu$ s laser pulses. For the $1-\mu$ s pulse, the laser power initially rises to about $1,500 \mathrm{~W}$ at $500 \mathrm{~ns}$ and then falls to the steady state value of $300 \mathrm{~W}$ after $1 \mu \mathrm{s}$. The overall pulse gradually decays to zero after $10 \mu \mathrm{s}$. For the $15-\mu$ s pulse, the same initial spike and the same decaying pattern at the end of the pulse are observed. However, the laser power rebounds to about $500 \mathrm{~W}$ after $1 \mu$ s and then settles to the steady state power of $300 \mathrm{~W}$ for an additional $14 \mu$ s. The initial spike was marked by a red line in a zoom-in plot in Figure 1.

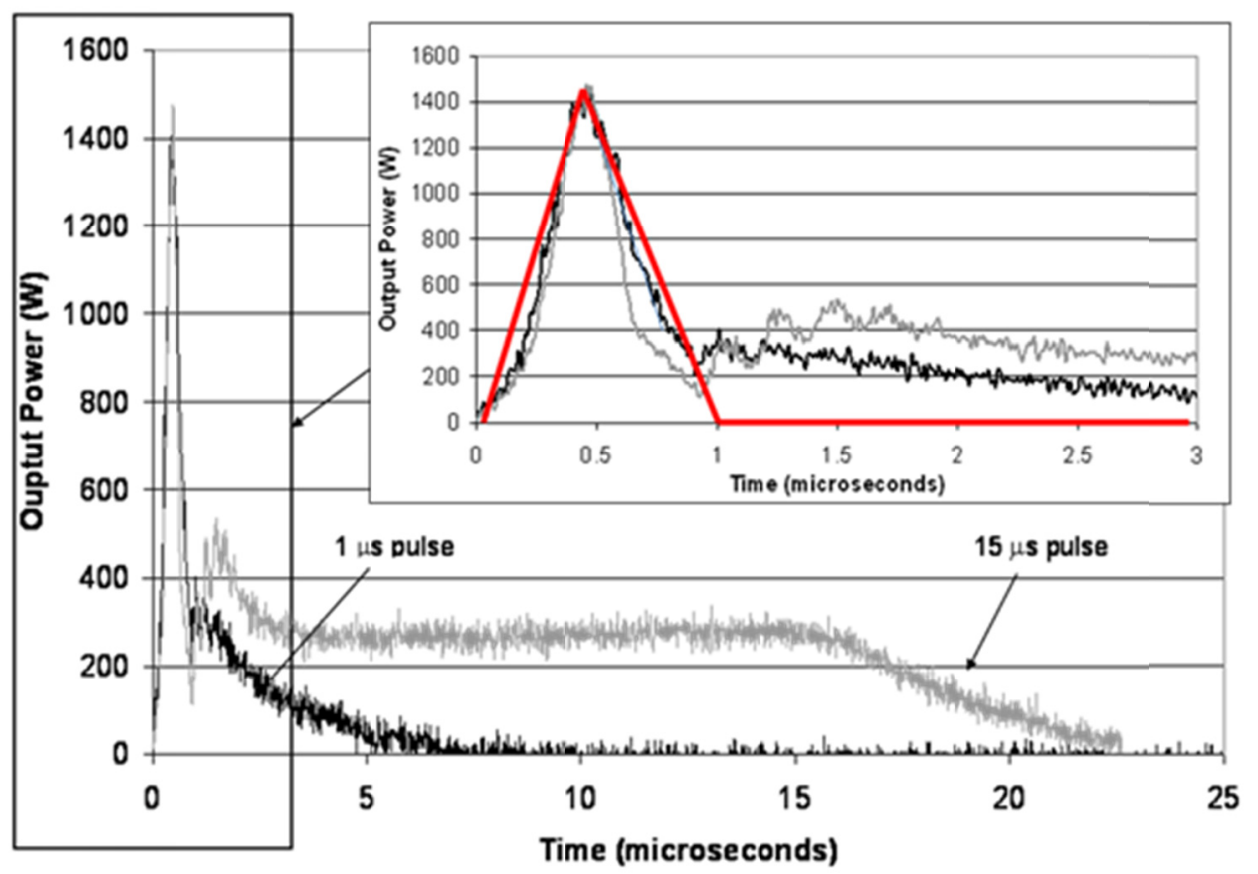

Figure 1. Laser pulse profiles of the $1-\mu \mathrm{s}$ and $15-\mu$ s pulses. Both pulses have an identical initial spike at 1,500 W which is approximately five times of the steady state value of $300 \mathrm{~W}$ 


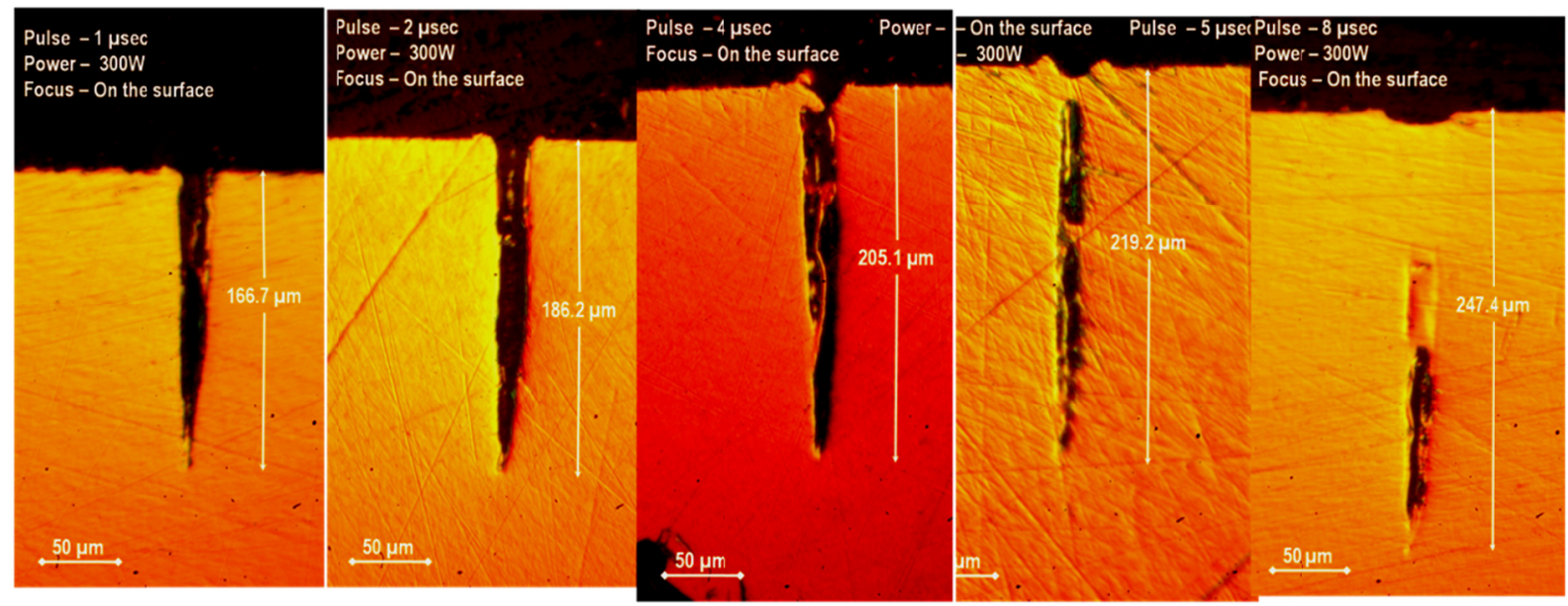

Figure 2. Hole geometry by the 1, 2, 4, 5, and 8 microsecond pulses

\subsection{Micro-Hole Geometry}

Typical profiles of micro-holes produced by a single pulse with pulse durations at $1,2,4,5$, and $8 \mu$ s are shown in Figure 2. For the hole produced by the $1 \mu \mathrm{s}$ pulse, the diameter of the hole is $18.9 \mu \mathrm{m}$ and the depth of the hole is $166.7 \mu \mathrm{m}$, equivalent to an aspect ratio of 8.8. The result of Figure 2 is a significant improvement over the previous results reported in Harp et al. (2008). Overall, the excellent hole profile and the narrow opening diameter is mainly due to the excellent beam quality of the single-mode fiber laser. It is clear that longer laser pulses produce deeper holes while the hole diameter does not increase substantially. The melt ejection becomes less effective when the hole depth reaches $200 \mu \mathrm{m}$ as hole opening blockage starts to appear. With 5 and $8 \mu \mathrm{s}$ pulses, the hole is completely blocked.

\section{Time Line of the Drilling Process with a Short Micro-Second Pulse}

\subsection{The First 5 Microseconds}

Two silicon photodiodes (Hammatsu S1336-18BQ) were used to measure the intensity evolution of the vapour/plasma plume when the laser was irradiated on the substrate. The response time of this photodiode is $5 \mathrm{~ns}$. A tube was placed around the photodiode sensors in order to aim at the vapour plume precisely. A short-pass filter (Thorlabs FES0900) was placed in front of the photodiodes to cut off radiations above $900 \mathrm{~nm}$ so that the laser radiation $(1075 \mathrm{~nm})$ would not affect the measurement of the plasma radiation. Two photodiodes arranged at different angles were used, one at a steep angle and one parallel to the plate. The photodiode measurements and the laser beam temporal profile were shown in Figure 3. The laser pulse started at $t=0$, and rapidly reached its peak power at about $500 \mathrm{~ns}$. The vapour/plasma signal was first detected at $200 \mathrm{~ns}$. This delay was related to the laser/material interaction time needed to evaporate and dissociate the material from the solid phase to hot vapour/plasma. This observation is consistant with the result reported by Trippe et al. (2004), in which the time needed to cause evaporation is found to be $100 \mathrm{~ns}$. The vapour/plasma continued to grow in intensity and reached to its peak at about 600-800 ns. After the peak, the vapour/plasma intensity decreased to nearly zero at $2.8 \mu \mathrm{s}$ as indicated by the silicon photodiode parallel to the plate, while some spurts of intensity were still registered by the steep angle photodiode. This was because the steep angle photodiode could observe the plasma trapped inside the hole. At this time, the laser power dropped below $200 \mathrm{~W}$. Another observation based on Figure 3 , was that, under the current setup, laser power less than $200 \mathrm{~W}$ was not capable of producing a vapour/plasma with intensity high enough to be registered by the parallel photodiode. After $5 \mu$ s, the laser power dropped to below $100 \mathrm{~W}$ and down to zero after about $10 \mu \mathrm{s}$. One reason for this is probably not due to the steep cavity which was already formed so that the incident angle of the laser beam to the substrate is far from 90 degrees to reduce the energy absorption efficiency. 


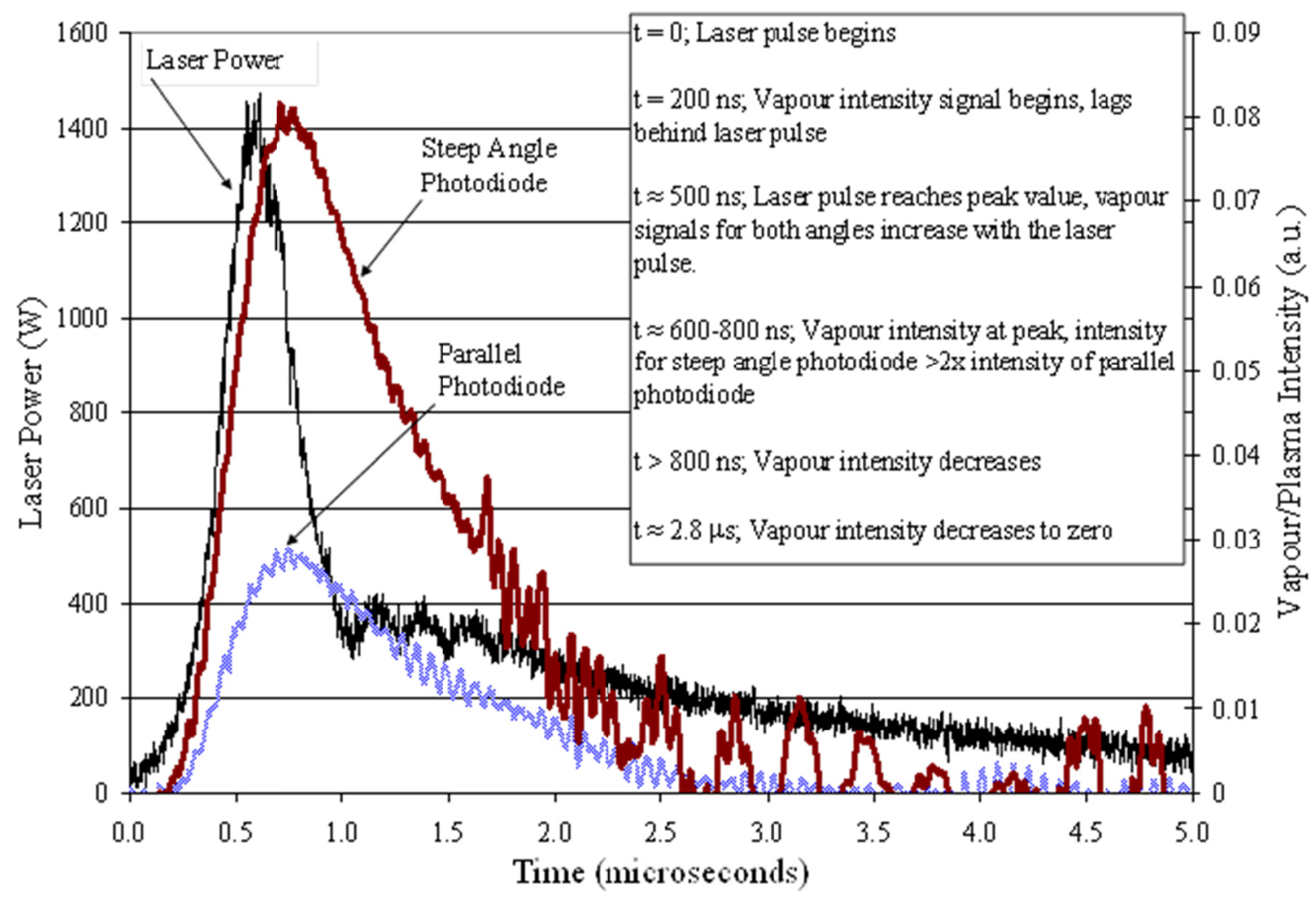

Figure 3. Vapour/plasma and laser intensity measurements

\subsection{Entire Process Time Line}

Although the photodiodes could not detect any signals after about $10 \mu \mathrm{s}$, it did not mean the drilling process had completed. To observe the entire drilling process, a high speed camera was used. The frame rate of this high speed camera was 40,500 frames/second; thus, the time interval between each frame was $24.6 \mu$ s. The camera was started before the laser radiation and took continuous frames of images throughout the drilling process. The high speed photography images were shown in Figure 4. If we set the start of the laser pulse as $t=0$, the first image of Figure 4 occurred some time between 0 to $24.6 \mu \mathrm{s}$ because the camera was not synchronized with the start of the laser radiation. We denoted the first frame time as $t_{1}$, as shown in Figure 4 and $0<t_{1}<24.6 \mu$ s. In the first frame, a coherent white flash started. Similar white flash was also observed in frames \#2 to \#4, which is 72 $\mu \mathrm{s}$ later. In the first four frames, the CCD sensor of the high speed camera was obviously saturated. At frame \#5, the white flash reduced to be gray and became fainter in frames \#6 and \#7, $144 \mu$ s later. It was not clear if the white flash in frame \#1 is the high intensity vapour/plasma observed in Figure 3 . Note that the high intensity vapour/plasma in Figure 3 was no longer detectable by the photodiodes after $3 \mu$ s when the vapour/plasma intensity became too low to be registered by the photodiodes. However, the intensity of the vapour/plasma might be too low for photodiodes after $3 \mu \mathrm{s}$, it was still strong enough to saturate the CCD sensor of the high speed camera. Because similar saturated white flashes were still observed in frames \#2-\#4, it was most likely that the first frame did not capture the high intensity vapour/plasma indicated in Figure 3. As shown in the red vapour intensity line in Figure 4, the vapour/plasma was very intensive within the first $3 \mu \mathrm{s}$, it then decayed gradually into weaker vapour and disappeared after almost $100 \mu \mathrm{s}$. In the second frame $\left(t=t_{1}+24 \mu \mathrm{s}\right.$, where $t_{1}$ is the time for the first frame), ejection of particles could be seen, which continued in the subsequent frames. Particles became visible in frames \#6 and 7. 


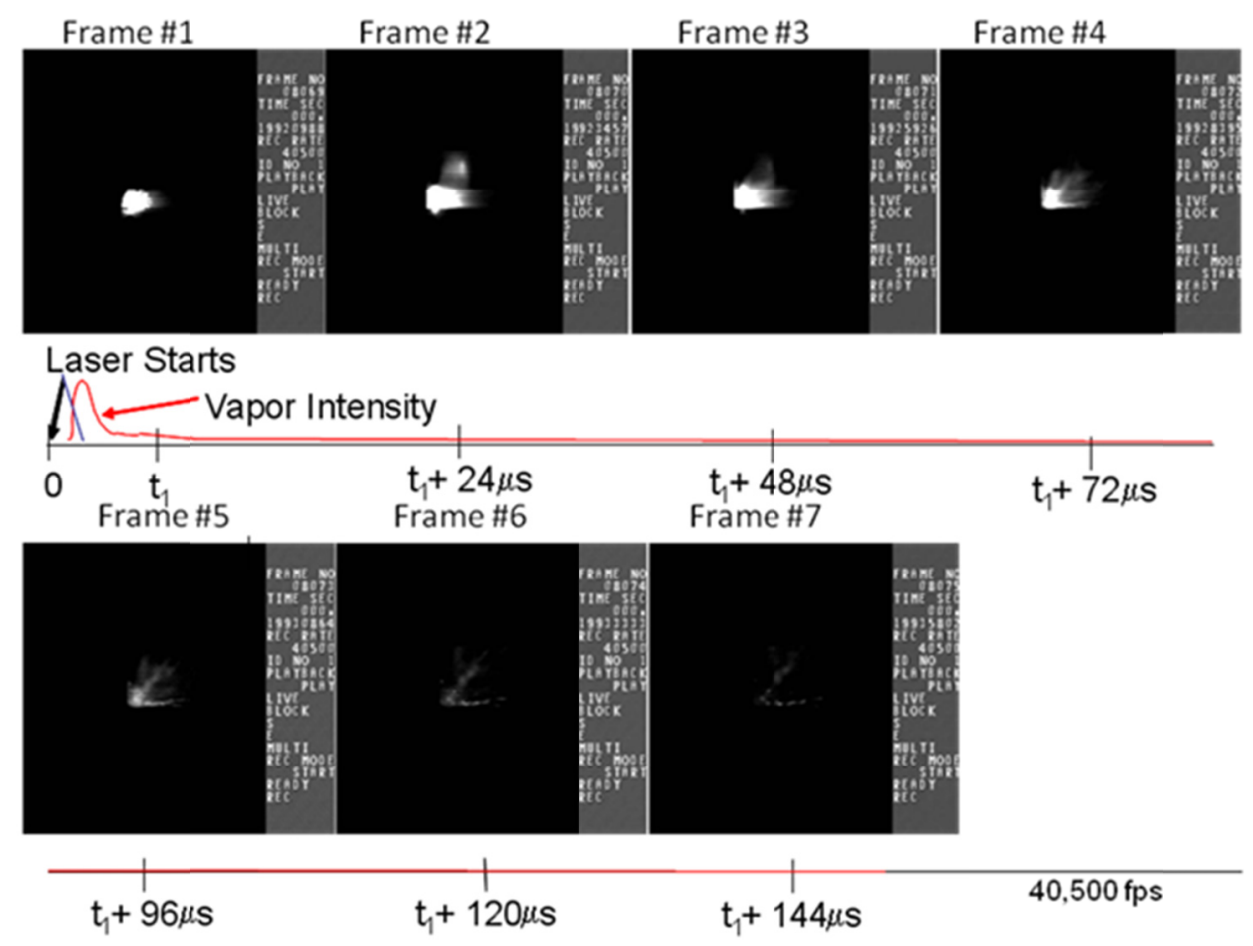

Figure 4. High speed images of the vapour produced during laser drilling

Based on Figure 4, the laser pulse was completed in $10 \mu$ s but the entire drilling process did not complete until more than $144 \mu$ s later. Due to the existence of vapour long after the laser pulse, we had to conclude that significant melting occurred and the white flashes captured by the high speed camera were low temperature vapour hovering over molten metal. The rise and decay of the vapour/plasma was plotted in Figure 4 in a red line under the high speed camera images.

\subsection{Spectroscopic Analysis of the Initial Vapour/Plasma}

A spectrometer was used to characterize the hot vapour/plasma at the beginning of the process. Three different tests were conducted for producing different vapour/plasma conditions, which included the single pulse drilling at $1,500 \mathrm{~W}$ and $1050 \mathrm{~W}$, as well as $\mathrm{CW}$ welding at $1 \mathrm{~mm} / \mathrm{s}$ at $300 \mathrm{~W}$. For the first two cases, the hot vapour/plasma was not at steady state but expanding. Measuring expanding plasma was difficult and very poor signal to noise ratio was expected. We did not present detailed information of the spectrometer measurements in this paper because of page limit. Table 1 listed the calculated peak vapour/plasma temperature based on $\mathrm{Cr}$ I spectral lines to reduce errors due to self-absorption.

It is important to note here that the error listed was estimated based on the uncertainty in the transition probabilities of some of the chromium lines. The error represented the worst case scenario, assuming that the transition probabilities of the lines were off by the maximum amount.

Table 1. Electron temperatures (in Kelvin) calculated from Boltzmann plots (95\% confidence level)

\begin{tabular}{ll}
\hline & Using Cr I lines \\
\hline $1 \mu$ s pulsing, $1,500 \mathrm{~W}$ & $43,611 \pm 27,623$ \\
$1 \mu \mathrm{s}$ pulsing, $1,050 \mathrm{~W}$ & $29,482 \pm 12,624$ \\
$1 \mathrm{~mm} / \mathrm{s}$ welding, $300 \mathrm{~W}$ & $8,290 \pm 998$ \\
\hline
\end{tabular}

According to Table 1, with $95 \%$ confidence level, the plasma temperature at the quasi-static welding condition at $300 \mathrm{~W}$ was estimated to be 7,000 to $9,000 \mathrm{~K}$. The peak temperature of the expanding vapour/plasma was estimated to be between $17,000-42,000 \mathrm{~K}$ at a peak power of $1,050 \mathrm{~W}$ and $16,000 \mathrm{~K}-71,000 \mathrm{~K}$ at $1,500 \mathrm{~W}$ peak 
power. Based on the results of Table 1, we can conclude that a hot vapour/plasma over $16,000 \mathrm{~K}$ and as high as $71,000 \mathrm{~K} \mathrm{did}$ exist in the first $1 \mu$ s of the process during the laser initial spike. Note that even at the highest temperature estimated in Table 1, the vapour/plasma was still optically thin with respect to the fiber laser wavelength of $1075 \mathrm{~nm}$. Therefore, the study of Table 1 also allows us to conclude that the laser beam did not heat the vapour/plasma and nearly all laser energy was used to either evaporate or to melt the material. The vapour temperature measured for the steady state welding condition at $300 \mathrm{~W}$ indicated that a weaker vapour at temperature between 7,000 to 9,000 K could exist at the later stage of the drilling process.

\subsection{Melt Ejection and the Expanding Vapour/Plasma}

The existence of a high temperature vapour/plasma indicates that its pressure would be high as well. Because the micro-hole was covered by this high temperature and high pressure plasma, the melt is likely to be superheated in the early stage of the drilling process. As the vapour/plasma cooled down to weaker vapour (after at least 24 microseconds), the pressure also dropped. The drop of pressure could cause the superheated melt to boil and to eject as fine droplets as seen in the high speed images of Figure 4.

\section{The Hole Formation Simulation during the First One Microsecond}

Figures 3 and 4 provide the timeline of this drilling process; however, the actual hole formation could not be observed directly. Therefore, computer simulation based on a 3D finite-element thermo-hydrodynamic model was used to study the hole formation due to evaporation by the initial laser spike.

\subsection{D Finite-Element Thermo-Hydrodynamic Model}

This 3D finite-element based thermo-hydrodynamic model accounts for the effect of multiple reflections inside the cavity, the movement of the liquid-vapour interface in time, the effect of recoil pressure on the liquid-vapour interface and the mass loss by evaporation during the drilling process (Ohmura \& Noguchi, 2010).

The model contained the continuity, Navier-Stokes and energy equations:

$$
\begin{gathered}
\nabla \cdot \vec{v}=0 \\
\rho\left[\frac{\partial \vec{v}}{\partial t}+(\vec{v} \cdot \nabla) \vec{v}\right]=-\nabla p+\mu \nabla^{2} \vec{v}+\vec{F} \\
\rho\left[\frac{\partial H}{\partial t}+(\vec{v} \cdot \nabla) H\right]=\nabla \cdot\left(\frac{k}{c_{p}} \nabla H\right)+w
\end{gathered}
$$

where $\mathrm{v}$ was the velocity vector of the material in the molten state, $\rho$ was the density of the material, $\mathrm{p}$ was the pressure, $\mu$ is the material viscosity, F comprised the body force vector for all the recoil pressure force and the surface tension force at work on an element of material, $H$ was the enthalpy, $k$ was the thermal conductivity, $c_{p}$ was the specific heat and $\mathrm{w}$ is the source term which was the heat input into the system by the laser.

The computational domain (Figure 5) was a 3D rectangular domain with the $\mathrm{z}$ axis parallel to the axis of propagation for the laser beam and the $x-y$ plane parallel to the material surface. The bounds of the domain are: $\mathrm{x}(-42 \mu \mathrm{m},+42 \mu \mathrm{m}), \mathrm{y}(-42 \mu \mathrm{m},+42 \mu \mathrm{m}), \mathrm{z}(-180 \mu \mathrm{m},+30 \mu \mathrm{m})$. The plane $\mathrm{z}=0$ was considered the surface of the material and the point $(0,0,0)$ was the center of the laser beam where it irradiated at the surface (see Figure 5 , indicated by a blue dot). The whole domain is at the room temperature as the initial condition and the boundaries of the domain remain at the room temperature during the simulation. The laser beam was considered to be Gaussian in space. A triangular function was used to approximate the actual laser pulse shape (the red profile in Figure 1) so that only the effect of the initial spike was simulated. The conditions at the material boundaries were considered to be insulated with zero flow velocity.

The model used a volume of fluid (VOF) method for handling of the liquid-vapour interface by computing the volume fraction of liquid, $\mathrm{F}$, in each element. The range of $\mathrm{F}$ was from 0 to 1 , with a value of 0.5 indicating that the element was an interface element. As the interface position was calculated, the normal vectors to the surface were determined and used to compute the angle of reflection for the surface. Using the Fresnel equation, the reflection coefficient was determined for each surface and the amount of reflected energy was calculated. 


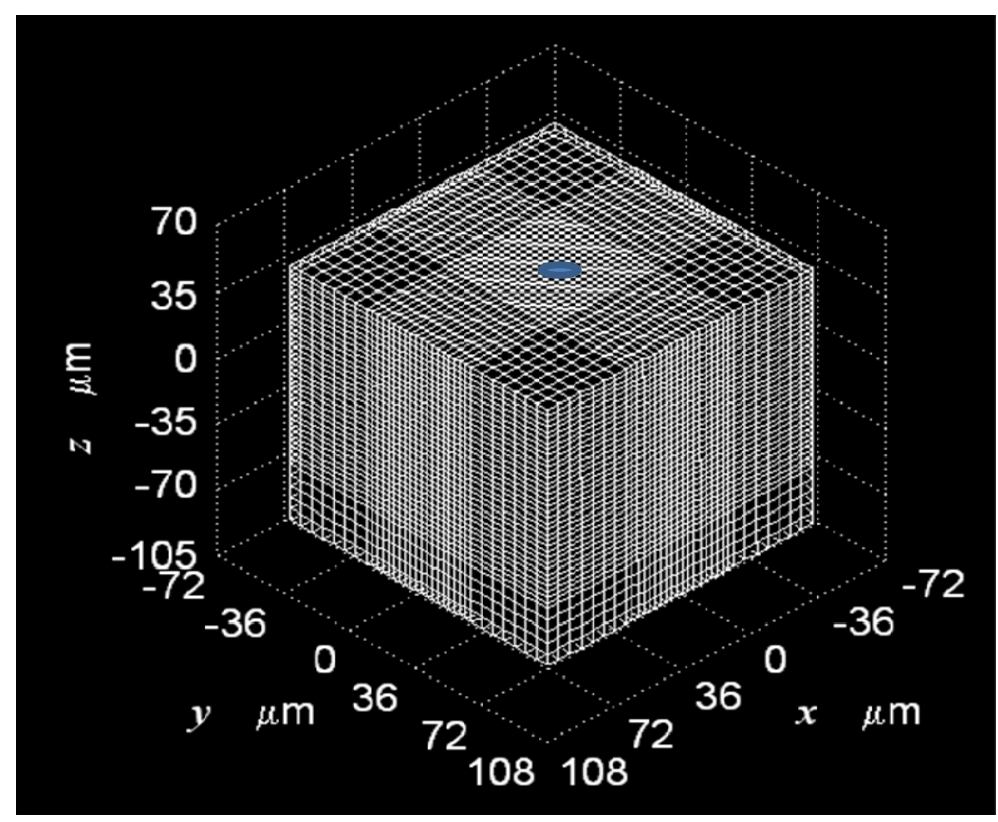

Figure 5. Computational domain

It was also assumed that, when the surface material was vaporized, the vaporized mass carried energy with it and traveled away from the surface. The amount of mass vaporized was calculated using an energy balance along the surface of the material.

$$
m_{v}=\frac{\int_{t}^{t+\Delta t} Q d t+\left.\int_{t}^{t+\Delta t} \int_{S} \frac{k}{c_{p}} \frac{\partial H}{\partial n}\right|_{S_{i n}} d S d t}{L_{v}}
$$

where $\mathrm{m}_{\mathrm{v}}$ was the mass of the vaporized material, $\mathrm{Q}$ was the laser power absorbed at the surface area $\mathrm{S}$ and $\mathrm{L}_{\mathrm{v}}$ was the latent heat of vaporization.

As the vaporized mass traveled away from the surface, it generated a recoil pressure on the surface. To calculate the recoil pressure generated by the vaporization of the material, the recoil pressure, $\mathrm{p}_{\mathrm{r}}$, was determined as the mass evaporated per unit area per unit time multiplied by the velocity of the vapour:

$$
p_{r}=\frac{m_{v}}{S \Delta t} v_{T}
$$

where $\mathrm{v}_{\mathrm{T}}$ was the vapour velocity at the edge of the Knudsen layer and was defined by Anisimov et al. (1971) as one-quarter of the square mean velocity:

$$
v_{T}=\frac{1}{4} \sqrt{\frac{8 k_{b} T_{d}}{\pi m_{a}}}
$$

where $T_{d}$ was the surface temperature and $m_{a}$ is the atomic mass of the vapour. This generated recoil pressure created a force on the surface of the material and acted against the surface tension force. These two forces acted as surface forces, whereas the momentum equation (Equation 2) required the input to be body forces. To convert the surface forces to body forces a continuum surface force (CSF) model was used (Brackbill, 1992).

The pressure-correction method for the flow velocity-pressure coupling used was the Simplified Marker-And-Cell (SMAC) method by Harlow and Amsden (1971). The algorithm for the model involved a series of steps. The first step was to calculate the normal vectors for the surface. Next, the surface forces were converted to body forces through the CSF method and used in the momentum equation, which was solved with the continuity equation through the SMAC method. The volume liquid fraction was then determined for the elements and the multiple reflections were calculated for the walls of the hole. The energy absorbed at the 
surface was used as the input source in the energy equation, in which the enthalpy was computed. The vaporized mass and the recoil pressure were then calculated. The time step was then advanced and the computations re-performed until the simulation was completed.

In summary, this model assumes that energy coupling between the laser and the material was mainly through the Fresnel absorption. The absorption became more efficient as the cavity forms, which allowed multiple reflections of the laser beam. When the material was removed by the evaporation process, only a portion of the absorbed energy was conducted away in the radial direction. Some laser energy used to induce melting in the radial direction could be reclaimed by the advance of the cavity as an adiabatic evaporation process. In other words, if a material mass was evaporated due to the irradiation of a laser beam with a very high power density, this mass could be super-heated and dissociated into plasma, consistent with the measurements discussed in Section 4.

\subsection{Hole Formation Simulation}

Figure 6 illustrates the formation of the hole in different time steps by the simulation. The simulation condition matched the experimental condition using a 1- $\mu$ s pulse as shown in Figure 1, except that the pulse profile is simplified as the red line profile in Figure (1). In this simplified profile, the pulse drops to zero at $1 \mu \mathrm{s}$. This profile was used to study the effect of the initial spike alone. The hole was seen to form very quickly during the laser pulse, but stopped abruptly when the pulse ended at $1 \mu \mathrm{s}$. This result was due to a simplified laser profile was used and only evaporation was considered as the material removal mechanism by this model. The contribution of the model is its ability to show the evolution of the hole formation via adiabatic evaporation, which is not observable via experimentation.

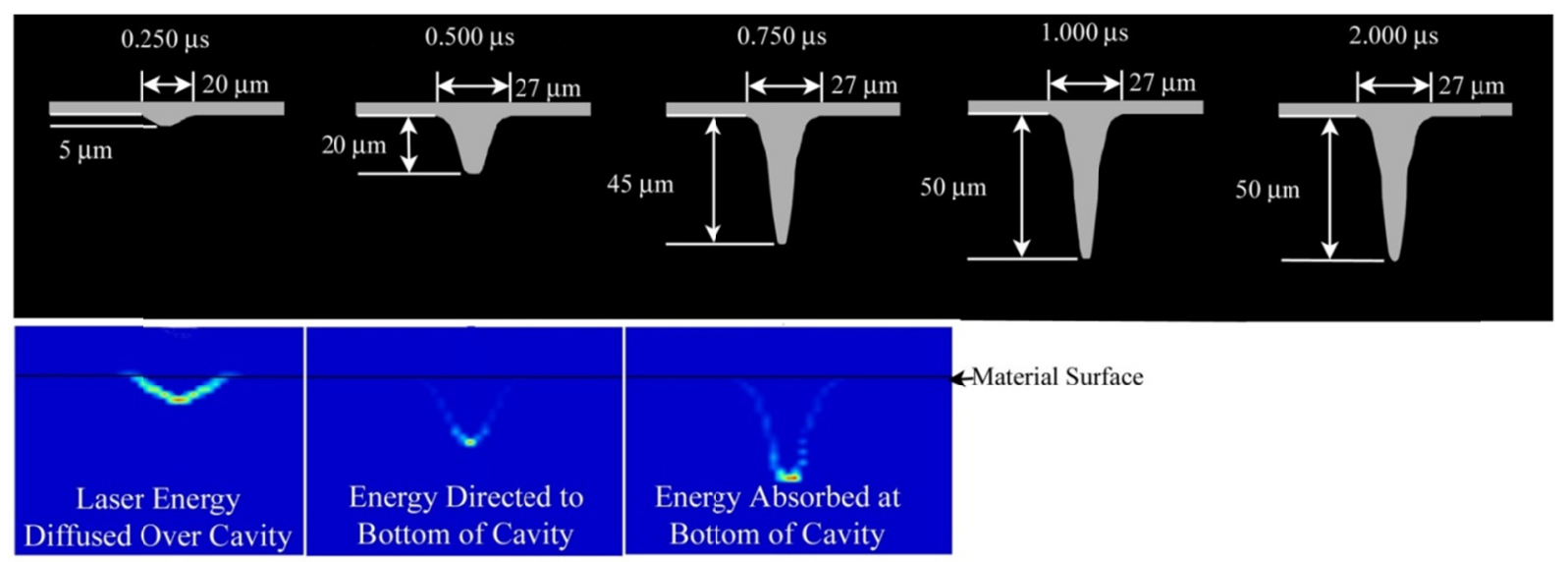

Figure 6. Hole formation by adiabatic evaporation by simulation

According to Figure 6, the opening diameter of the hole did not change after $500 \mathrm{~ns}$, which indicated that little heat transfer occurred in the radial direction once the hole was established. This could also be explained by multiple reflections as shown in bottom figures in Figure 6. Once the hole became sufficiently deep, the laser energy was reflected to the bottom of the cavity to further deepen the hole.

Another interesting observation of Figure 6 was that the majority of material removal by adiabatic evaporation was completed by $750 \mathrm{~ns}$. Because the evaporated material received a large amount of laser energy deposited by the initial laser spike, it was dissociated into hot plasma, as confirmed in Section 4.3. This result was also consistent with the measurement of vapour/plasma intensity which peaks at about 600 to 800 ns (Figure 3).

\subsection{Data and Model Comparison}

The experimentally obtained hole had a depth of $166.7 \mu \mathrm{m}$, an opening diameter of $18.9 \mu \mathrm{m}$, and an aspect ratio of 8.8 (Figure 2). In comparison, the simulation produced a hole with a depth of $50 \mu \mathrm{m}$, a diameter of $27 \mu \mathrm{m}$, and an aspect ratio of 1.8. Therefore, the simulation produced a hole wider and shallower than the experimental result. As the model considered only the adiabatic evaporation, the discrepancy between the experiment and simulation indicated the important role of other mechanisms neglected by the model, such as the laser energy deposited after $1 \mu \mathrm{s}$, melt ejection, explosive boiling, and the energy re-radiated by the vapour/plasma. With this comparison, the adiabatic evaporation mechanism is estimated to contribute to about $1 / 3$ of the material removal. 


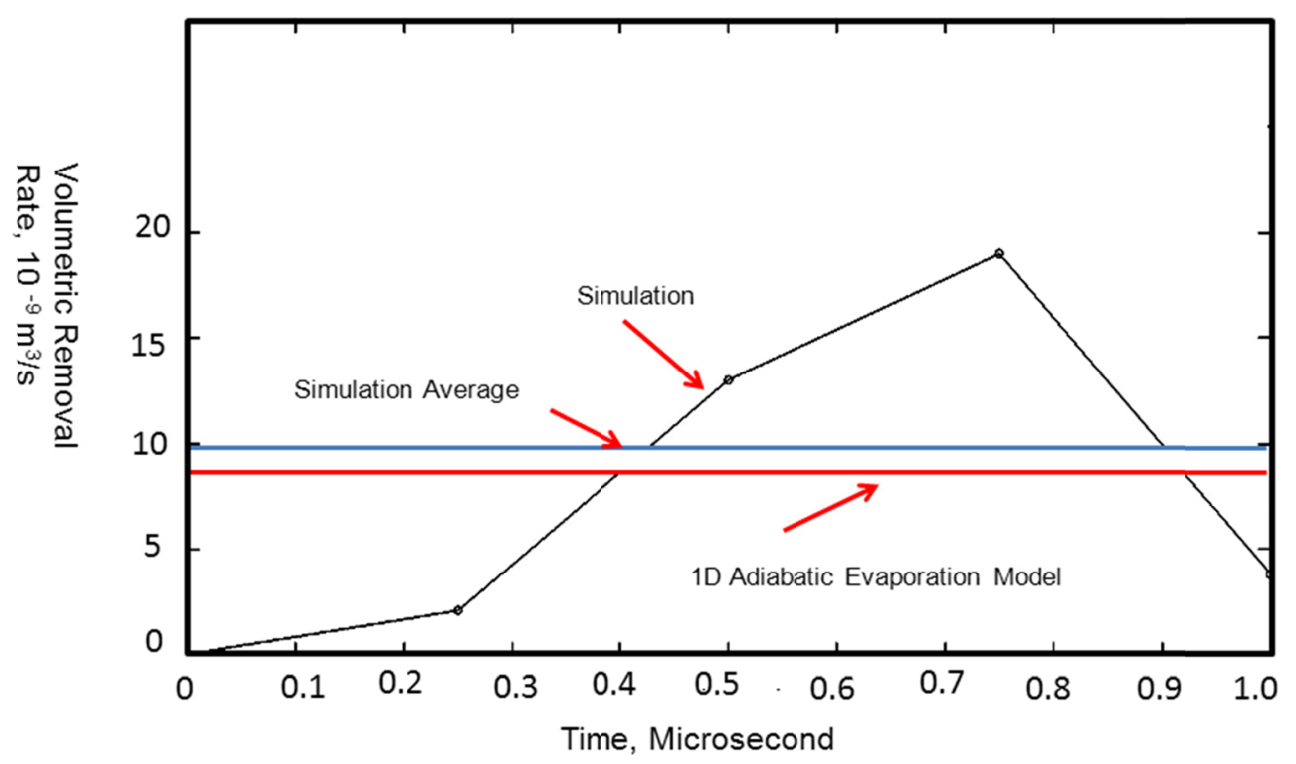

Figure 7. Volumetric removal rate comparison

Figure 7 plots the Volumetric Material Removal Rate (VMRR) during the early hole formation. To provide a comparison, a one-dimensional drilling model by von Allmen and Blatter (1995) was used to calculate its VMRR. This model assumes that adiabatic evaporation occurs at the bottom of a cylindrical volume; thus, there is no heat transfer in the radial direction. Based on this model, the drilling speed equation is:

$$
u=I_{a} \frac{V_{d}}{\Delta H\left(T_{d}\right)+\Delta H_{L V}}
$$

where $I_{a}$ was the absorbed power density, $V_{d}$ is the molar volume, $\Delta H\left(T_{d}\right)$ was the enthalpy needed to reach the surface temperature $\mathrm{T}_{\mathrm{d}}$, and $\Delta \mathrm{H}_{\mathrm{LV}}$ was the enthalpy of vaporization. Using an absorbed laser power of $800 \mathrm{~W}$, which was the average value of the laser power over the pulse, and the area of the cylinder equal to the beam spot size, the corresponding VMRR was calculated to be $8.81 \times 10^{-9} \mathrm{~m}^{3} / \mathrm{s}$, which was also plotted in Figure 7 . According to Figure 7, the VMRR predicted by the 1D model was only slightly lower than the average value of the 3D simulation. Because these two predictions matched each other very well, the mechanism of adiabatic evaporation could be assumed in the early stage (before 750ns) of the drilling process. The fact that the actual hole depth was much deeper than that of the simulated hole, it again suggested significant contribution of material removal by mechanisms other than evaporation.

\section{Other Material Removal Mechanisms}

Based on the analysis in Section 5, it is estimated that adiabatic evaporation contributes to only $1 / 3$ of the actual hole formation. The roles of other material removal mechanisms, such as the laser energy deposited after $1 \mu \mathrm{s}$, melt ejection, explosive boiling, and the energy re-radiation by the vapour/plasma, need to be identified.

\subsection{Material Removal by Laser Energy Deposited at a Lower Laser Power}

The effect of the laser energy deposited after $1 \mu$ s at a low laser power was determined in this section. In Figure 8 , a $1-\mu$ s pulse was plotted against a $4-\mu$ s pulse. For the $1-\mu$ s pulse, the laser energy deposited between $1-10 \mu \mathrm{s}$ (the area below the laser power curve) was calculated to be approximately $2.4 \mathrm{~mJ}$, while the energy deposited in the first $1 \mu \mathrm{s}$ was $0.8 \mathrm{~mJ}$. The laser energy deposited at this low laser power period was not able to produce high temperature plasma (Figure 3 ) but it could induce melting and mild evaporation to advance the hole depth.

To determine the material removal by the lower power energy, we compared the holes produced by a 1, 2, 4, 5 and 8 - $\mu$ s pulses (Figure 2). The additional energy deposited by longer laser pulses was $0.3,0.9,1.2$, and $2.1 \mathrm{~mJ}$, respectively. The extra laser energies led to $19.5,38.4,52.5$, and $80.7 \mu \mathrm{m}$ additional hole depth, respectively. Dividing the additional depth by the additional energy, we obtained an average depth versus additional energy ratio as $65.00,42.6,43.8$, and $38.4 \mu \mathrm{m} / \mathrm{mJ}$, respectively. It appeared that the energy deposited near the initial 
spike was more effective. It should be noted that the energy deposited after the initial spike in a $1-\mu$ s pulse was not at a constant power. Due to this fact, we use the average of the above ratios, $47.2 \mu \mathrm{m} / \mathrm{mJ}$, for estimation. Based on this averaged ratio, the additional energy deposited between 1 to $10 \mu \mathrm{s}(2.4 \mathrm{~mJ})$ for a $1-\mu \mathrm{s}$ laser pulse likely contributed to $113 \mu \mathrm{m}$, which accounted for $68 \%$ of the total hole depth of $166.7 \mu \mathrm{m}$. On the other hand, based on the simulation, the initial spike of the $1-\mu$ s likely was responsible for $30 \%$ of the hole drilling (50 $\mu \mathrm{m}$ of $166.7 \mu \mathrm{m})$. Both results were consistent.

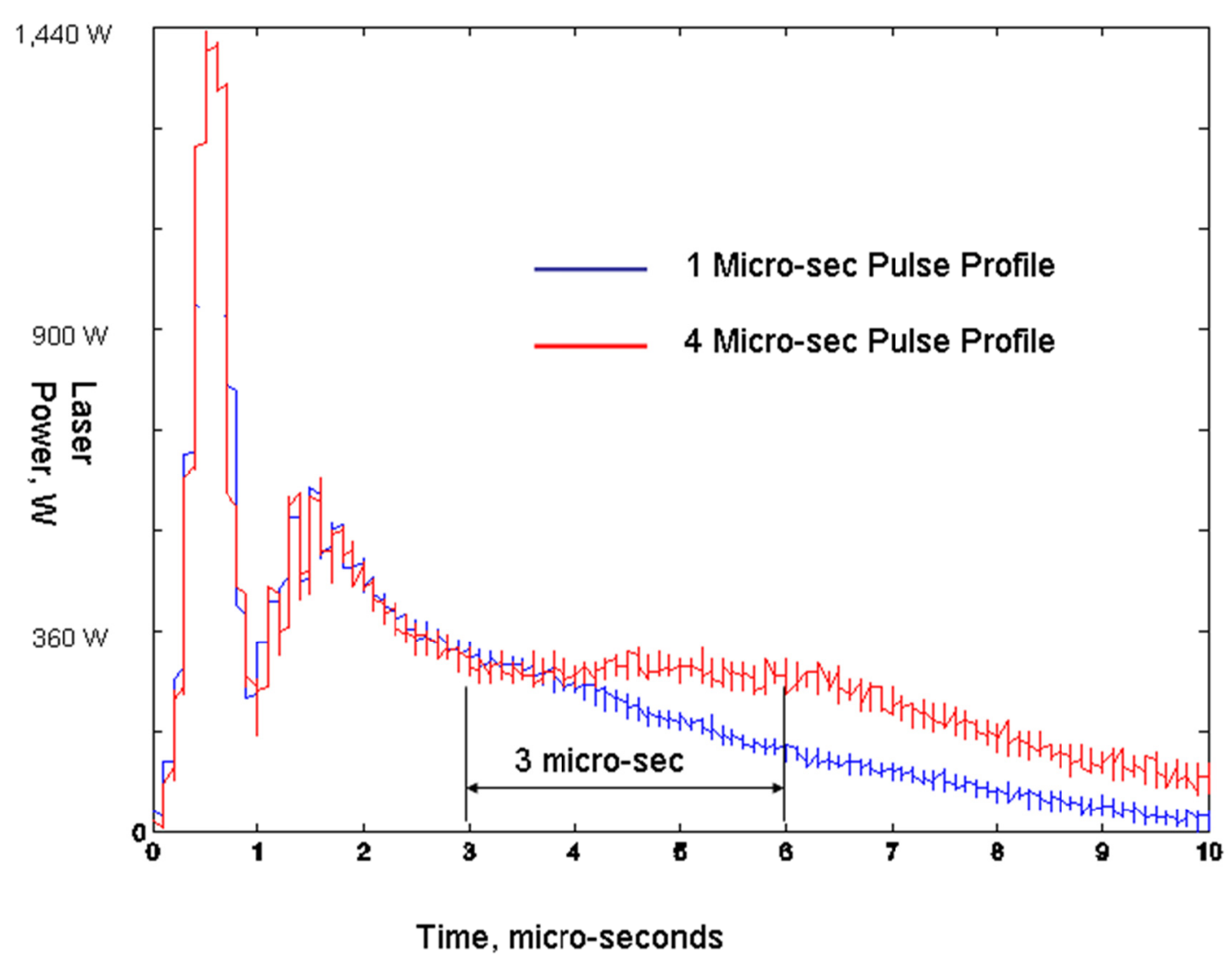

Figure 8. Energy difference between two pulse durations

However, material removal by melting needs effective melt ejection mechanisms. As shown in Figure 2, with laser pulses over $5-\mu$ s and hole depth over $220 \mu \mathrm{m}$, significant blockage at the opening by re-solidified melt started to appear.

\subsection{Melt Ejection}

As the hole depth became deeper, it would take more pressure to drive the melt at the bottom of the hole upward and out of the hole. This melt ejection process must be effective in order to keep the blink hole open at the top. In this study, we did not attempt to improve melt ejection by an assist gas jet, blowing side way to enhance melt ejection. However, such strategy should be investigated for multiple-pulse drilling to achieve hole depth over 1 $\mathrm{mm}$ or aspect ratio over 20.

\section{Three Media Interactions}

From the above analysis, it became evident that the drilling investigated in this paper involved three media, laser, bulk material, and vapour/plasma. Regarding energy sources for this drilling process, the highly focused laser beam was the primary energy source, depositing energy at two different power levels, while the vapour/plasma was a secondary energy source, which re-radiate some energy back to the bulk material to promote melting and is the only energy source after $10 \mu \mathrm{s}$. Note that all energy came from the laser beam, but the vapour/plasma helped to preserve some energy. A discussion of the interactions between these three media is in order. 


\subsection{Laser/Bulk Material Interaction}

Initial Laser Spike on the Bulk Material: The initial spike $(1,500 \mathrm{~W})$ of the laser beam offered sufficient power density to initiate a cavity into the bulk material through adiabatic evaporation (Figure 6). As the energy absorbed by this evaporated material far exceeded the latent heat of the material due to very high laser power density $\left(\sim \mathrm{GW} / \mathrm{cm}^{2}\right)$, it superheated and partially ionized the vapour into hot and high pressure plasma at about $16,000-71,000 \mathrm{~K}$. The expansion of this vapour/plasma also compressed the ambient air to form a shock wave which it expanded. A popping sound was clearly audible during the drilling process. The initial spike was estimated to produce $1 / 3$ of the depth of the micro-hole.

The Bulk Cavity on the Laser: The cavity of the bulk material created favorable multiple reflections to direct substantial portion of the laser beam toward the cavity bottom to further deepen the cavity (Figure 6).

Lower Power Laser on the Bulk Material: As the laser beam power fell from its peak to the steady state power $(300 \mathrm{~W})$, the power density of the laser beam was no longer sufficient to evaporate and ionize the bulk into hot plasma. Therefore, the energy deposited by the lower power laser beam inside the cavity mainly was used to create superheated melt inside the cavity. Without further feeding, the vapour/plasma started to cool (Figure 3). The hole depth contributed by the lower power portion was estimated to be $2 / 3$ of the total hole depth.

Melt on the Laser Beam: Due to multiple reflections, substantial amount of laser energy was directed toward the bottom of the cavity (Figure 6) and the lower beam power contributed more melt at the bottom. On the other hand, because of its lower reflectivity, the melt could absorb the beam energy more efficiently, cutting down the beam reflection. As a result, as the hole became deeper, the laser energy that could be delivered to the hole bottom became less and the hole drilling became less effective. As shown in Figure 2, a 4- $\mu$ s laser pulse contained about $30 \%$ more energy than that of a $1-\mu$ s pulse; however, it only produced $16 \%$ more in hole depth.

\section{Three Media Interaction}

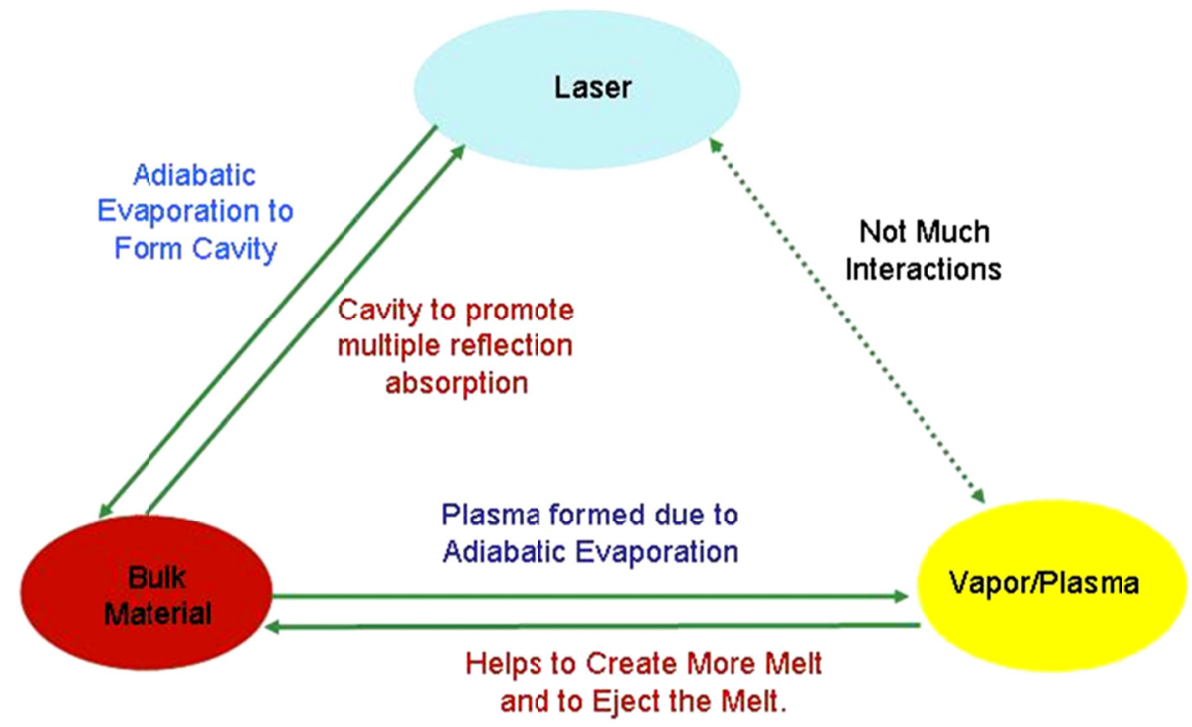

Figure 9. Interaction among three media during rapid micro-hole drilling

\subsection{Laser/Vapour-Plasma Interaction}

Laser Heating of Vapour/Plasma: The IB absorption coefficient calculated based on the electron temperature also indicates low laser/plasma interaction (Table 1) even at the peak temperature of the vapour/plama. The laser beam did not heat the vapour/plasma directly and the energy contained in the plasma was originally absorbed via the laser/bulk interaction. The above statement is also supported by the photo-diode measurement of the plasma. For example, in the one-microsecond ablation, the measurement of the plasma emission dropped to almost zero at approximately 3 micro-second even though the laser power stayed over $200 \mathrm{~W}$ during the same time period (Figure 3).

Vapour/Plasma on Laser Beam: Based on the plasma measurement of Table 1, the existence of plasma inside the 
cavity likely did not block or affect the laser/bulk interaction.

\subsection{Vapour-Plasma/Bulk Interaction}

As the high temperature plasma was a high energy source in itself, the plasma re-irradiated some of its energy back to the bulk material to enhance the hole drilling. The high pressure, coupled with the high temperature plasma, might also allow the superheating of the melt. Subsequently, the melt would boil when the pressure dropped as the plasma expanded and exited out of the cavity. The reduction of pressure promoted explosive ejection of melts as fine droplets long after the laser irradiation, as observed in Figure 4.

\section{Process Anatomy}

Based on the experimental and simulation results presented in previous sections, a temporal process anatomy diagram of the short microsecond laser drilling, using the single-mode fiber laser, was compiled. Four stages of the process were depicted in Figure 10, from shortly after the laser irradiation to long after the completion of the laser irradiation. This process anatomy diagram was also color-coded to illustrate corresponding temperatures during the process. This process anatomy diagram summarizes the laser/material interaction mechanisms, hole formation, material removal mechanisms, and vapour/plasma characterization as discussed in the previous sections. A summary of time line, together with the process anatomy, is discussed below:

$$
\mathrm{t}=250 \mathrm{~ns}
$$

Laser Power $600 \mathrm{~W}$

Shallow Cavity Formed

$$
\mathrm{t}=500 \mathrm{~ns}
$$

Laser Peak $1500 \mathrm{~W}$

Vapour/Plasma Intensity $80 \%$ of maximum

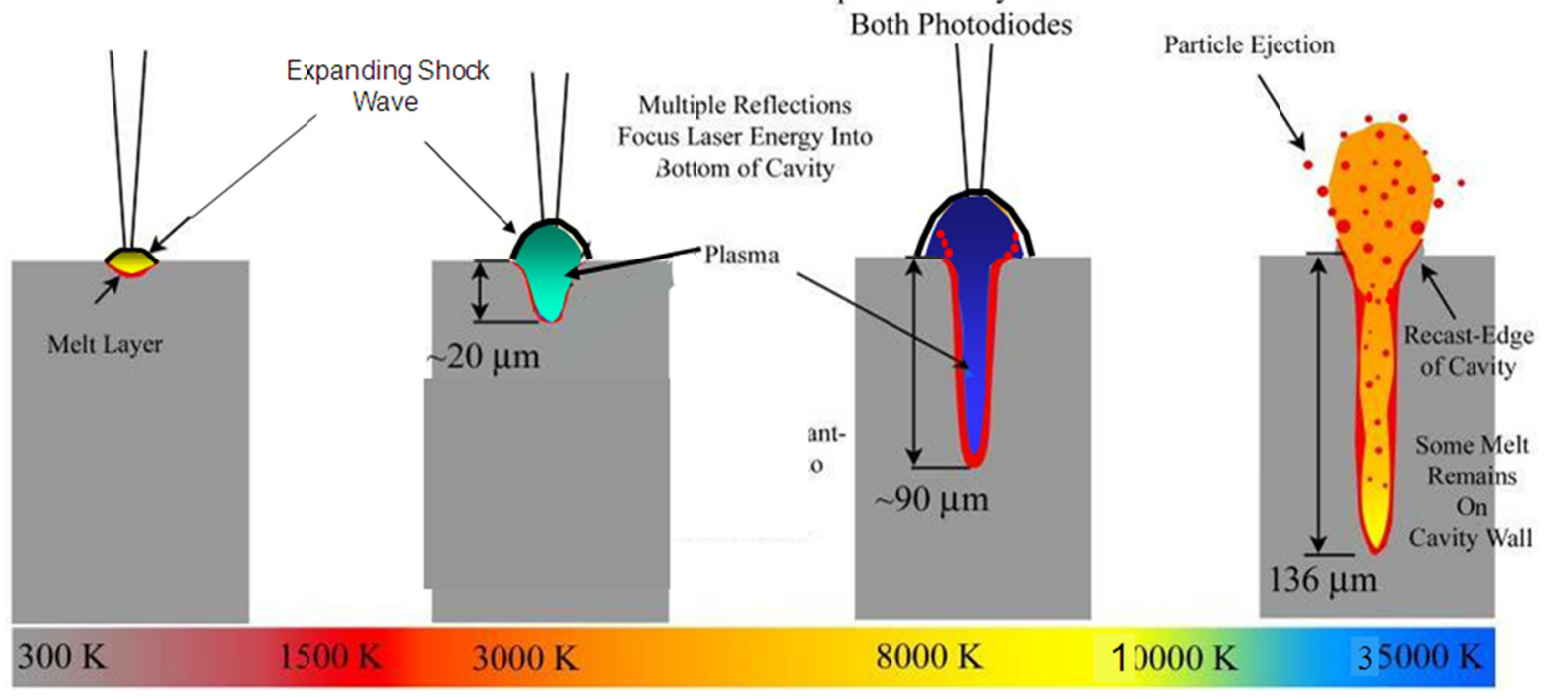

Figure 10. Process anatomy of the rapid drilling process using a one micro-second laser pluse generated by a single-mode $\mathrm{CW}$ fiber laser

Stage $1(0 \sim 250 \mathrm{~ns})$ (Process Anatomy Diagram \#1): The laser power rapidly increased to be high enough to evaporate a small amount of solid into hot vapour/plasma, first detected at $200 \mathrm{~ns}$. At $250 \mathrm{~ns}$, the laser power was $600 \mathrm{~W}$ and the cavity was estimated to be $5 \mu \mathrm{m}$ deep (Figures 3 and 6).

Stage 2 (250 500 ns) (Process Anatomy Diagram \#2): The intensity of the vapour/plasma continued to grow along with the increase of the laser power. When the laser power increased to its peak value of $1,500 \mathrm{~W}$ at $500 \mathrm{~ns}$, the vapour signal reached $1 / 4$ of its peak intensity. The hole was deepened to $20 \mu \mathrm{m}$.

Stage $3(500 \mu \mathrm{s} \sim 1 \mu \mathrm{s})$ (Process Anatomy Diagram \#3): The laser power rapidly dropped from its peak to about $400 \mathrm{~W}$ at $1 \mu \mathrm{s}$. However, the vapour/plasma intensity continued to grow and reached its peak value at about 600 to $800 \mathrm{~ns}$. After $800 \mathrm{~ns}$, the vapour/plasma intensity started to drop. Based on the electron temperature measurements and subsequent calculations of the electron density and absorption coefficient, the vapour/plasma was optically thin and the laser energy could be deposited over the cavity wall without being absorbed by the vapour/plasma, even at its peak. The hole was deepened to $50 \mu \mathrm{m}$ by evaporation alone. 
Stage $4(1 \mu \mathrm{s} \sim 2.5 \mu \mathrm{s})$ (Process Anatomy Diagram \#4): The laser power fell to its steady state $(300 \mathrm{~W})$ at $2.5 \mu \mathrm{s}$. The vapour/plasma intensity continued to fall but at a slower rate than that of the laser power. The intensity of the vapour/plasma was still high enough to be registered by the photodiodes, which indicated that its temperature was still high, so was its pressure. The melt produced by the laser at the cavity wall was likely super-heated because it was covered by the high temperature and high pressure vapour/plasma. The hole continued to deepen via mild evaporation and melting.

Stage $5(2.5 \mu \mathrm{s} \sim 10 \mu \mathrm{s})$ (Process Anatomy Diagram \#4): Laser power dropped below $200 \mathrm{~W}$ and continued to drop to zero after $10 \mu \mathrm{s}$. At $2.8 \mu \mathrm{s}$, plasma had turned into weaker vapour, not detected by the horizontal photo-diode. The laser energy deposited at lower power could still produce some spurts of vapour/plasma inside the micro-hole registered by the steep angle photodiode. This part of laser energy deposited at lower power most likely produced more melt than vapour. The hole continued to deepen mostly via melting.

Stage $6(10 \mu \mathrm{s} \sim 80 \mu \mathrm{s})$ (Process Anatomy Diagram \#4): No laser energy was deposited in this stage, but hot vapour still covered the micro-hole. This intensity of this hot vapour was too low to be measured by the photodiodes but was high enough to saturate the CCD sensor of the high speed camera (first four frames of Figure 4. Therefore, the temperature of the vapour should be much lower than the vapour/plasma observed in Stages \#1-5 to render its pressure lower. The drop of vapour pressure likely would cause the superheated melt to boil and eject outward as seen in frames \#2-4 of Figure 4 and the $4^{\text {th }}$ process anatomy diagram. The hole likely stopped deepening and was partially filled with melt, ejecting upward and out.

Stage $7(80 \mu \mathrm{s} \sim 150 \mu \mathrm{s})$ : Vapour was no longer visible after around $80 \mu \mathrm{s}$. The last melt ejection was observed around $150 \mu \mathrm{s}$, which was the end of the drilling process. Some melt was re-solidified around the hole as recast.

\section{Conclusion}

This paper presented a single-pulse micro-hole drilling technique using short micro-second pulses by modulating a CW single-mode $300 \mathrm{~W}$ fiber laser. The capability of this drilling technique was demonstrated and several in-process monitoring experiments, such as photodiode measurements of the vapour intensity, high-speed photography, and spectroscopic plasma measurements, were used to identify the laser/material interaction mechanisms. For the drilling process with a $1-\mu$ s laser pulse, the process started with drastic evaporation and concluded with melt ejection approximately $150 \mu$ s later. It is concluded that two distinct drilling mechanisms occurred, one as adiabatic evaporation by the high power initial spike and one as melt ejection by the low power energy deposition. The time line of this drilling process was established experimentally based on measurements by several in-process sensors, such as photodiodes, a high-speed camera, and a spectrometer. The theoretical modeling zoomed in the early stage of the process to investigate the hole formation which could not be observed experimentally. Both experimental and theoretical results were then compared to determine the laser-material interaction mechanisms among three media involved in the process: laser, material, and vapour/plasma. Finally, a series of temporal anatomy diagrams, denoted as process anatomy, were presented to describe the entire drilling process by a one micro-second laser pulse. This process anatomy summarizes the laser/material interaction mechanisms, hole formation, material removal mechanisms, and vapour/plasma characterization of this short micro-second laser drilling process.

\section{Acknowledgments}

This investigation is supported by the Department of Mechanical and Aerospace Engineering at North Carolina State University, NSF Grants CMS-0402857, DMI-0355481, DMI-0355214, DMI-0944509. The authors would like to acknowledge the assistance of Prof. W. Roberts of MAE, NCSU for the loan of the high speed camera.

\section{References}

Bauerle, D. (2000). Laser Processing and Chemistry (3rd ed.). Springer. http://dx.doi.org/10.1007/978-3-662-04074-4

Brackbill, J. D., Kothe, D. B., \& Zemach, C. (1992). A continuum method for modeling surface tension. J. Comp. Phys., 100(2), 335-354. http://dx.doi.org/10.1016/0021-9991(92)90240-Y

Breitling, D., Ruf, A., \& Dausinger, F. (2004). Fundamental aspects in machining of metals with short and ultrashort laser pulses. Pro. SPIE, 5339, 49-63. http://dx.doi.org/10.1117/12.541434

Garnov, S. V., Konov, V. I., Kononenko, T., Pashinin, V. P., \& Sinyavski, M. N. (2004). Microsecond Laser Material Processing at $1.06 \mu \mathrm{m}$. Laser Physics, 14(6), 910-915.

Griem, H. R. (1964). Plasma Spectroscopy (1st ed.). New York: McGraw-Hill.

Harp, W. R., Dilwith, J. R., \& Tu, J. F. (2008). Laser ablation using long pulsed, high fluence, CW single mode 
fiber laser. Journal of Materials Processing Technology, 198(1), 22-30. http://dx.doi.org/10.1016/j.jmatprotec.2007.06.062

Harlow, F. H., \& Amsden, A. A. (1971). A numerical fluid dynamics calculation method for all flow speeds. $J$. Comp. Phys., 8, 197-213. http://dx.doi.org/10.1016/0021-9991(71)90002-7

Kayukov, S. V., Gusev, A. A, Zaichikov, E. G., \& Petrov, A. L. (1998). Drilling of narrow holes in metals by millisecond pulses of Nd:YAG lasers. Laser Physics, 8(2), 527-531.

Kreutz, E. W., Trippe, L., Walther, K., \& Poprawe, R. (2007). Process development and control of laser drilled and shaped holes in turbine components. Journal of Laser Micro/Nanoengineering, 2(2), 123-127.

Low, D., Li, L., \& Byrd, P. (2004). The influence of temporal pulse train modulation during laser percussion drilling. Opt Lasers Eng, 35, 149-164. http://dx.doi.org/10.1016/S0143-8166(01)00008-2

Low, D., \& Li, L. (2002). Effects of inter-pulse an d intra-pulse shaping during laser percussion drilling. Proc SPIE, 4426, 191-194. http://dx.doi.org/10.1117/12.456852

Mao, X., Wen, S., \& Russo, R. E. (2007). Time resolved laser-induced plasma dynamics. Applied Surface Science, 253, 6316-6321. http://dx.doi.org/10.1016/j.apsusc.2007.01.053

Ohmura, E., \& Noguchi, S. (2010). Laser drilling simulation considering multiple reflection of laser, evaporation and melt flow. In Andreas Öchsner, Lucas Filipe Martins da Silva, \& Holm Altenbach (Eds.), Materials with Complex Behaviour-Modelling, Simulation, Testing, and Applications, Advanced Structured Materials, 3, 297-310. Springer-Verlag.

Pandey, N. D., Shan, H. S., \& Bharti, A. (2006). Percussion drilling with laser: hole completion criterion. Int. J. Adv. Manuf. Technol., 28, 863-868.

Trippe, L., Willach, J., Kreutz, E. W., Schulz, W., Peteriet, J., Kaierle, S., \& Poprawe, R. (2004). Melt ejection during single-pulse drilling and percussion drilling of micro holes in stainless steel and nickel-based superalloy by pulsed Nd:YAG laser radiation. SPIE, 5662, 609-615.

Voisey, K. T., Klocker, T., \& Clyne, T. W. (2002). Measurement of melt ejection velocities during laser drilling, ACTA Materialia, 4219-4230. http://dx.doi.org/10.1016/S1359-6454(02)00249-5

Von Allmen, M., \& Blatter, A. (1995). Laser-Beam Interactions with Materials. Berlin: Springer. http://dx.doi.org/10.1007/978-3-642-57813-7

Walther, K., Brajdic, M., \& Freutz, E. W. (2008). Enhanced processing speed in laser drilling of stainless steel by spatially and temporally supported pulsed Nd:YAG laser radiation. Int. J. Adv. Manuf. Technol., 35, 895-899. http://dx.doi.org/10.1007/s00170-006-0768-z

\section{Copyrights}

Copyright for this article is retained by the author(s), with first publication rights granted to the journal.

This is an open-access article distributed under the terms and conditions of the Creative Commons Attribution license (http://creativecommons.org/licenses/by/3.0/). 